\title{
PATHOLOGICAL ENLARGEMENT OF RESIN CANALS IN PICEA
}

\author{
J. B. Prince, \\ Forest Products Laboratories, Forest Service, \\ Department of the Interior.
}

$\mathrm{T}$

HE object of this paper is to describe an abnormal character encountered in Engelmann spruce (Picca Engelmanni, Engelm.) and in white spruce (Picea glauca, Voss) sampled for testing at the Forest Products Laboratories of Canada, Forest Service, Department of the Interior, Ottawa.

The unusual character is the presence of greatly enlarged horizontal resin canals in the wood. The size of some of the abnormal canals is so great that their presence is easily detected by visual inspection of the tangential faces of the wood specimens. In a great many cases the canals appear as large as or even larger than the widest pores of oak. Their occurrence also appears to be noticeable on the bark, the exterior surface of which is covered with whitish spots like small circular lenticels. Microscopic examination of tangential sections of the wood shows that the area immediately surrounding the enlarged canals is somewhat distorted, the neighbouring tracheid walls being compressed and forced out of their usual alignment. Sanio's trabeculae are of very frequent occurrence in the abnormal wood, radial sections of which usually reveal several series distributed in the neighbourhood of the enlarged canals.

The radial resin canals in normal wood of Engelmann spruce average about 50 microns in diameter (Plate 1, fig. 1). In the abnormal wood of the tree under discussion the diameter of the enlarged ducts ranges between 100 microns and 800 microns (Plates I. छ II., figs. 4 छ 8).

While horizontal resin canals in the abnormal area are greatly enlarged, the vertical canals appear to be normal. (Plate I., fig. 3). A transverse section, therefore, shows no unusual features except when cut along the path of one of the fusiform rays.

There was sufficient material of the abnormal tree to permit anatomical study of various regions of the main stem. Complete cross sections of the Engelmann spruce trunk several inches in thickness were available for examination, and as these disc samples had been taken at 8-foot intervals from the butt to the top of the tree, it was possible to map the occurrence of normal and abnormal wood. The regions showing the abnormal character are indicated by the diagrams figured in the text.

Examination of the discs representing the various levels shows that the abnormal tree began life by producing wood that appears normal in all particulars (Plate I, fig. 2). In the lowest disc of the trunk (taken 3 feet from 
the ground) the abnormality is first noticeable at about the forty-ffth annual layer, the abnormal ducts being confined to the outer two hundred growth rings.

It will be noted that once the abnormality appeared its production was perpetuated and in this respect its occurrence bears considerable resemblance to the so-called "bird's-eye" structure of maple (Acer saccharum) and other species, which according to Hale (2) is produced by a fungus in the cambium.

It is obvious that whatever caused the abnormality noted in Engelmann spruce must have acted upon the cambium. The agency of a parasitic fungus at once suggests itself. In the first place the cambium is a region rich enough in food supply to tempt its occupation by parasitic fungi. Moreover, there are fungus parasites already known which effect abnormal increases in the size of the rays of infected plants. (Ref. Wörnle (7), Hyde (5), Hartig (4)).

The horizontal resin ducts formed after injury in Cedrus (Jeffrey (6), Forsaith (2)), are often very similar to the abnormal ducts noted in Engelmann spruce.

Evidence for the fungal origin of the enlarged ducts of Engelmann spruce is presented by the presence of Sanio's trabeculae in the abnormal regions. Sanio's trabeculae, according to Hale (2) are caused by cambial fungi, and the presence of the rod-like structures which traverse the cavities of wood cells in long radial series is advanced by him as important evidence for the fungal origin of the "bird's-eye" structures of maple and other hardwoods and also for the fungal origin of the so-called "bear-scratches" of Sitka spruce (Picea sitchensis) and other softwoods.

The occurrence of Sanio's trabeculae in connection with the abnormal ducts was mentioned earlier in this paper and a series of these rod-like structures is figured in Plate II. (figures 5 and 6) in close relation to one of the enlarged ducts. Other isolated trabeculae of various forms are visible in other regions of the section. The frequent occurrence of trabeculae appears to furnish additional evidence that the abnormal ducts are due to the activity of a filamentous fungus in the tissue of the cambium.

Fungus filaments were found to be present in the cambium of the abnormal tree, but as the material was not examined in the laboratory before shipment from British Columbia, it is not possible to state definitely that the fungus might not have infected the cambium during shipment, although no appreciable infection of the cambium was noted in the other normal trees shipped at the same time.

The abnormal size of resin canals was accompanied by what seemed an excessive oleo-resin content of the wood. No quantitative analysis was made to determine the resin content, but it was noted that the excessive oleo-resinous 


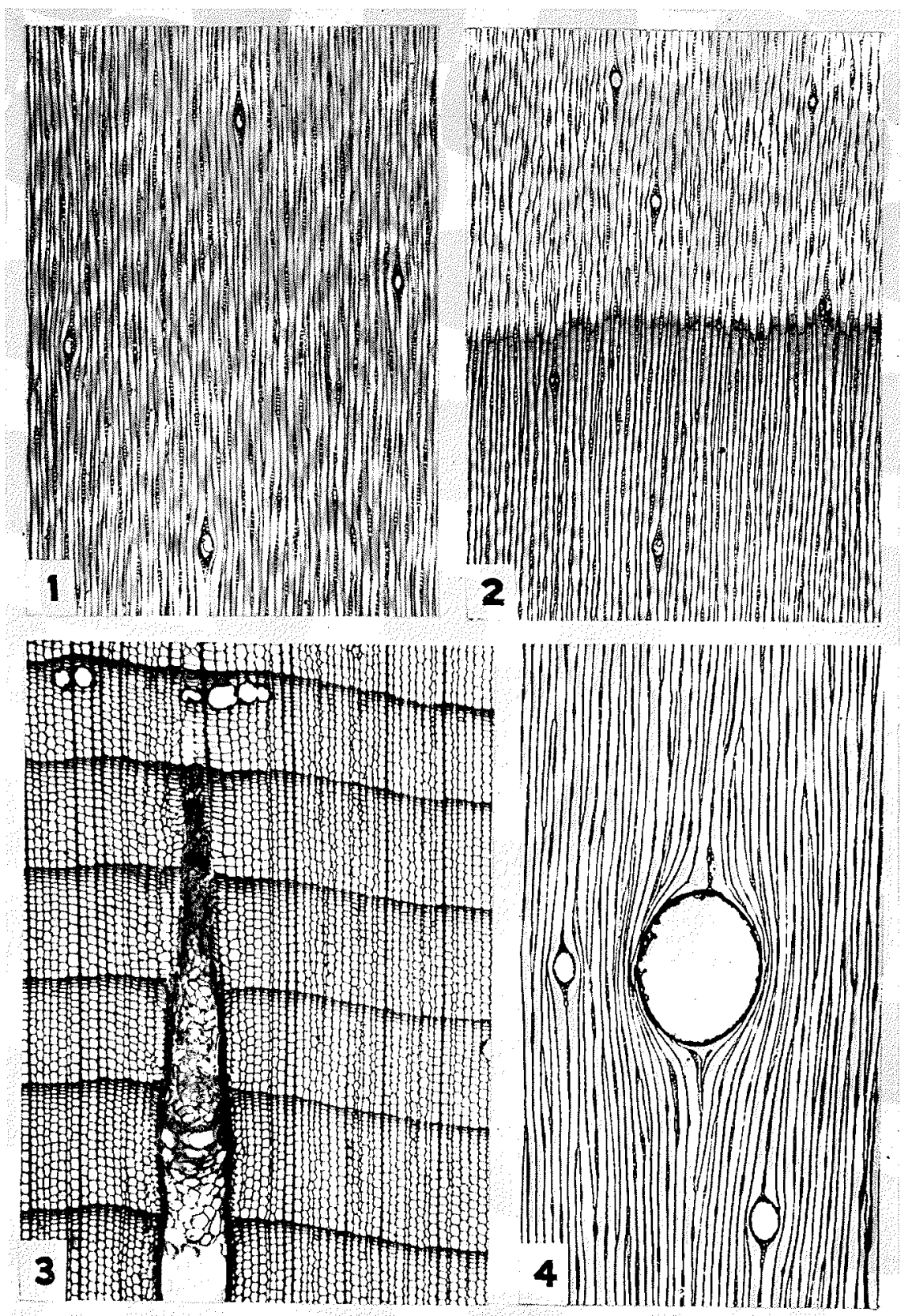

Plate I. 


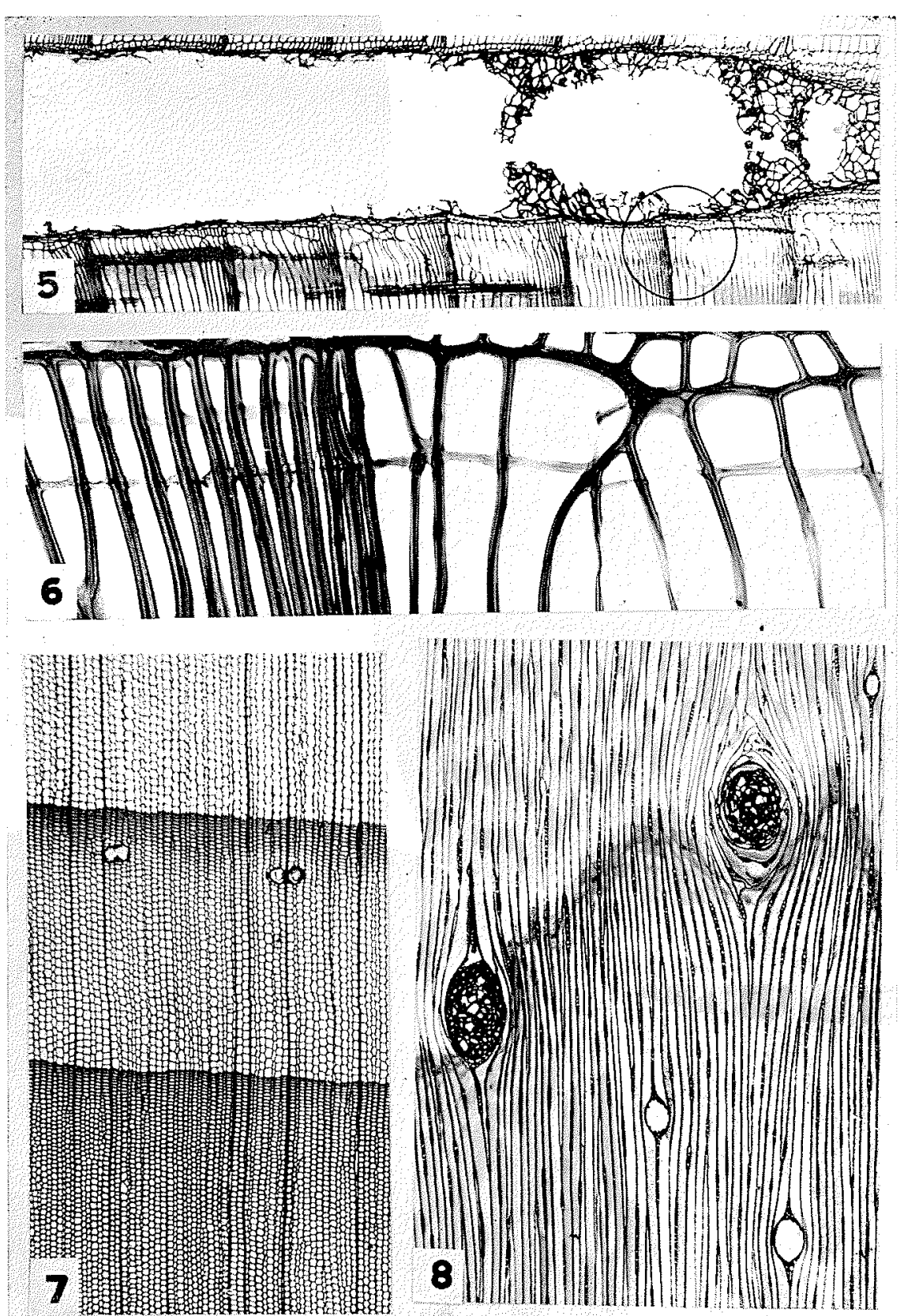

Plate II. 
exudation on the surface of the wood made it much more sticky to the touch than fresh sapwood of normal spruce, and microtome sections of fresh wood that were left in water exhibited a disagreeable tendency to stick together. It may be of some interest here to note the effect of the parasite Armillaria mellea, which causes "resin glut" of conifers, as recorded by Hartig (4) in its action in stimulating the production of traumatic resin canals in wood of infected trees before killing the host.

The same abnormal character of the horizontal ducts observed in Engelmann spruce was noted in a sample of white spruce of eastern Canada (Picea glauca) secured in the course of taking specimens from pulpwood logs at a local paper mill. As the sample was chipped from the surface of a log that was passing the observer beside the log conveyor there was no opportunity to study the history of the abnormal character in that particular specimen. The character in fact was not observed until the material was subsequently examined in the laboratory and its resemblance to the abnormal ducts of Engelmann spruce noted. Its occurrence in the outer wood of the tree was similar to the case of the tree of Engelmann spruce. The chip of white spruce contained numerous small pitch pockets in addition to the abnormal ducts, a character noted by Hartig in wood of trees infected with Armillaria mellea. Of importance in indicating the agency of a cambial fungus, Sanio's trabeculae were as conspicuously present as in the traumatic areas of the Engelmann spruce.

Whatever the stimulus causing the production of abnormal ducts in the tree of Engelmann spruce, it certainly did not result in the death of the tree, which continued to produce the abnormal character for some two hundred years previous to its felling. The sample of white spruce also appeared to be from a freshly felled live tree. It is not clear that the tree of Engelmann spruce showed any other abnormal character in this connection than the large resin ducts, although its wood was the lightest in weight of all eight trees shipped from its locality.

The average specific gravity of wood in the abnormal tree is 0.32 based upon the green volume and the oven-dry weight. The average for Canadian. grown Engelmann spruce of timber size, according to material tested at the Forest Products Laboratories of Canada, is in the neighbourhood of 0.35considerably heavier than the wood of the abnormal tree. However, the wood of the normal areas of this tree has also about the same low density as that of the abnormal areas. As the mean density of the tree is not so low as to place it outside the range of variation encountered in Engelmann spruce, its light weight may very probably be due to other causes than to a fungus infection of the cambium. 


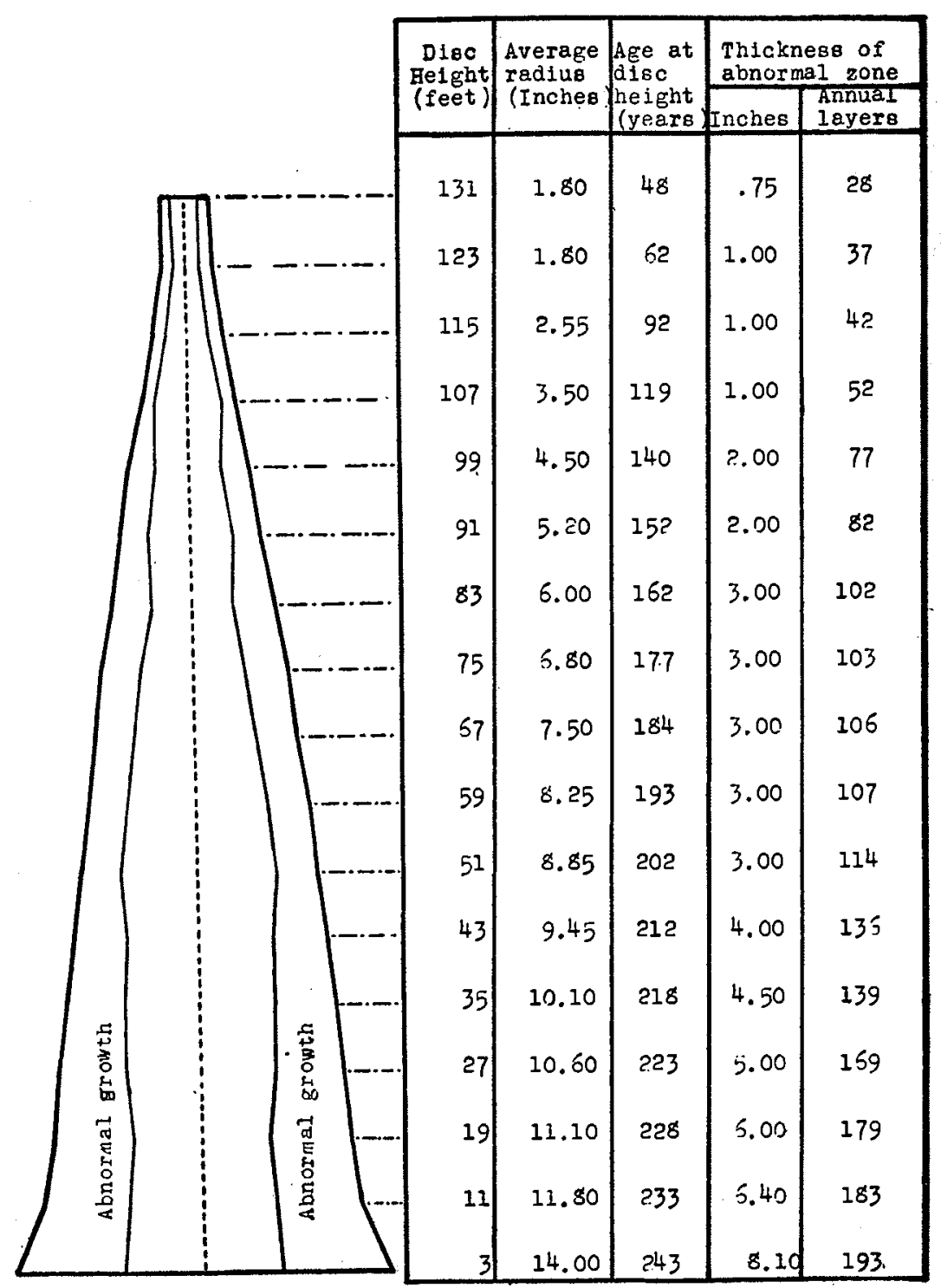

TEXT FIGURE:-Diagram showing regions of the trunk where the abnormal ducts occur with specific measurements of normal and abnormal areas.

The occurrence of the abnormal character of the horizontal resin ducts of spruce is of interest in that it is probably widespread even if not commonly encountered. However, so far as is known to the writer, the occurrence of 
this character over the trunk of a mature tree has not been previously described and is of special interest on this account as well as for the evidence of its fungal origin.

It is of interest to anatomists and mycologists in that the abnormal structure described here suggests that many such unusual structures in plants besides the more obvious disconformities such as galls, cankers, etc., are due to parasitic micro-organisms in the cambium.

These observations on the enlarged canals of Picea were made in the course of anatomical work at the Forest Products Laboratories.

TABULATED MEASUREMENTS OF CANAL DIAMETERS

\begin{tabular}{|c|c|c|c|c|c|c|c|c|}
\hline \multirow{4}{*}{$\begin{array}{l}\text { Height of } \\
\text { disc from } \\
\text { ground } \\
\text { (in ft.) }\end{array}$} & \multicolumn{8}{|c|}{ Diameter of abnormal canals in microns } \\
\hline & \multirow{2}{*}{\multicolumn{2}{|c|}{ Periphery }} & \multicolumn{6}{|c|}{ Distance from periphery (inches) } \\
\hline & & & \multicolumn{2}{|c|}{1} & \multicolumn{2}{|c|}{2} & \multicolumn{2}{|c|}{3} \\
\hline & Aver. & Range & Aver. & Range & Aver. & Range & Aver. & Range \\
\hline 3 & 150 & $100-150$ & 150 & $100-250$ & 160 & $100-300$ & 100 & $80-150$ \\
\hline 11 & 100 & $80-150$ & 160 & $100-400$ & 120 & $100-200$ & & \\
\hline 19 & 190 & $100-300$ & 210 & $100-450$ & 120 & $100-250$ & & \\
\hline 27 & 250 & $100-200$ & 170 & $100-500$ & 140 & $100-200$ & & \\
\hline 35 & 190 & $100-500$ & 230 & $100-500$ & 170 & $150-450$ & 110 & $100-150$ \\
\hline 43 & 280 & $150-600$ & 210 & $150-400$ & 210 & $150-350$ & & \\
\hline 51 & 320 & $150-450$ & 340 & $100-550$ & 190 & $150-250$ & & \\
\hline 59 & 350 & $100-800$ & 270 & $150-450$ & & & & \\
\hline 67 & 240 & $150-450$ & 280 & $150-500$ & & & & \\
\hline 75 & 250 & $150-700$ & 250 & $150-500$ & & & & \\
\hline 83 & 310 & $250-450$ & 230 & $150-400$ & & & & \\
\hline 91 & 200 & $150-300$ & 260 & $150-450$ & & & & \\
\hline
\end{tabular}

LITERATURE CITED

(1) Forsaith, C. C. Technical Bulletin 18. New York State College of

(2) Hale, J. D. Forestry at Syracuse University, page 76.

The identification of woods commonly used in Canada. Forest Service Bulletin 81, Forest Products Laboratories of Canada, Forest Service, Department of the Interior, Ottawa, p. 15.

(3) Hale, J. D. Trabeculae of Sanio-their origin and distribution. "Science," of February 2, 1923, p. 155. 
(4) Hartig, R.

Text-book of the diseases of trees. Translated by William Somerville. Published by "Country Life," London, England, page 210.

(5) Hyde, K. C. Anatomy of a gall on Populus trichocarpa. Botanical Gazette, vol. LXXIV., 1922, p. 186.

(6) Jeffrey, E. C.

The anatomy of woody plants. Published Oct., 1917, University of Chicago Press, p. 75.

(7) Wörnle,

Anatomische Untersuchungen der durch Gymnosporangium-Arten hervorgerufenen Missbildungen. (Forstl.Naturwiss. Zeitschr. 1894, 3, 68.) As reported by $E$. Kuster, Pathologische Pflanzenanatomie, page 196.

DESCRIPTION OF PLATES I. and II.

I.

Fig. 1 x35. Tangential section of normal Picea Engelmanni.

Fig. 2 x35. Normal wood of infected tree of Picea Engelmanni.

Fig. 3 x35. Transverse section of Picea Engelmanni with portion of an abnormal canal.

Fig. 4 x35. Tangential section of Picea Engelmanni showing abnormal canals.

II.

Fig. 5 x35. Radial section of Picea Engelmanni showing abnormal canal. Note series of Sanio's trabeculae below the resin canal.

Fig. $6 \times 350$. A portion of Fig. 5, enlarged, showing Sanio's trabeculae. (Region indicated by circle in fig. 5 ).

Fig. 7 x35. Transverse section of normal wood of Picea Engelmanni.

Fig. 8 x35. Tangential section of Picea Engelmanni showing abnormal canals.

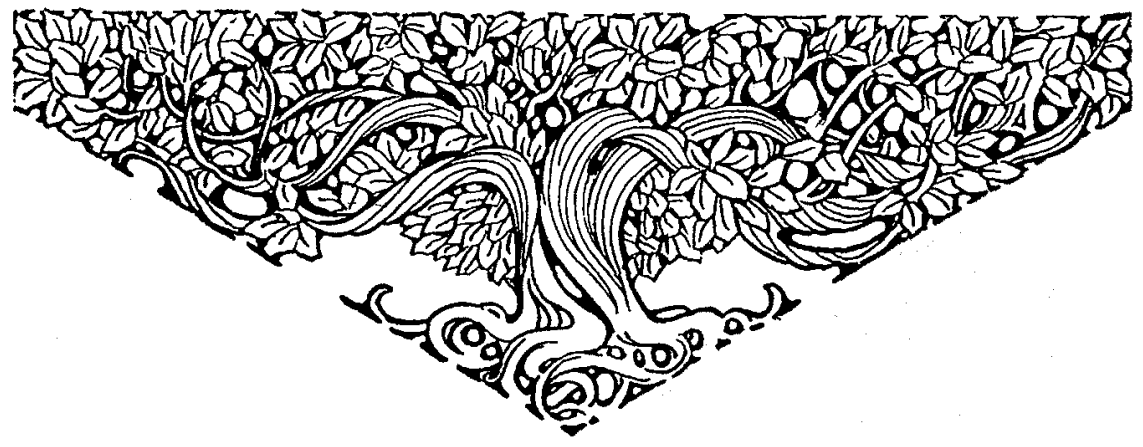

